\title{
The myth of ballistic processing: Evidence from Stroop's paradigm
}

\author{
DEREK BESNER \\ University of Waterloo, Waterloo, Ontario, Canada
}

\begin{abstract}
The Stroop effect is widely considered to be compelling evidence that skilled readers cannot prevent themselves from reading the irrelevant word or even delay such processing. In contrast, several reports indicate that the Stroop effect can be eliminated by various simple manipulations. These reports have been criticized on several grounds, among them that the baseline condition is suspect. These criticisms are addressed by showing that when (1) a neutral baseline is replaced by congruent trials, (2) single letter cuing and coloring manipulations are combined, (3) attentional window conditions are blocked, and (4) the congruent/incongruent trial ratio is 20/80, the Stroop effect is eliminated. A second major finding is that despite no Stroop effect, negative priming is observed, consistent with the hypothesis that a distinct but delayed perceptual act processes the word. The default set may be to process to the highest level (semantics), but these reading processes are (contextually) controlled rather than ballistic.
\end{abstract}

Many introductory psychology textbooks, specialized books and chapters on word recognition and reading, and refereed journal articles view the Stroop effect as compelling evidence that the mental processes that underlie skilled word recognition are ballistic. That is, the subject is seen as being unable to prevent such processes from being initiated and running to completion, even when they are irrelevant to the task at hand and can hurt performance. The thesis of the present line of investigation is that this widespread view is too strong; rather than word recognition processes being ballistic, they are strongly affected (controlled) by the local context.

I start with a brief description of the Stroop effect and note (1) some recent work concluding that processing need not be ballistic in this context, (2) criticisms of this conclusion, and then (3) report new experiments. The results of these experiments converge on the conclusion that, in the context of a variant of Stroop's paradigm, the Stroop effect can be eliminated ${ }^{1}$ and is therefore not ballistic. Finally, despite the absence of a Stroop effect, $n e g$ ative priming is observed in the same experiment. This result is consistent with the hypothesis that the irrelevant word is processed but by a separate perceptual act that is delayed relative to the word recognition processes that normally contribute to the Stroop effect on a current trial.

\section{The Stroop Effect}

There are many variations on Stroop's (1935) observation that identifying the color of an incongruent word

This paper was supported by Grant A0098 from the Natural Sciences and Engineering Council of Canada. I thank Jennifer Stolz and an anonymous reviewer for trenchant comments. Correspondence should be addressed to D. Besner, Psychology Department, University of Waterloo, Waterloo, ON, Canada N2L 3G1 (e-mail: dbesner@watarts.uwaterloo.ca). (e.g., the word green displayed in red) in a list is much slower than identifying the color of a control character list (MacLeod, 1991, 1992). Contemporary variants typically consist of a discrete trial procedure in which the subject is presented with a word that is displayed in a color that is either congruent or incongruent with the word's meaning, and subjects are asked to identify the color and ignore the word. The standard result is that the incongruent condition is slower than the congruent condition. The flavor of contemporary thought is captured here:

... there is good evidence that skilled readers obligatorily process printed stimuli when [they are] presented to the fovea, even if they intend to ignore [them], and even if it interferes with a competing task (Stroop, 1935). Thus, we argue that the presentation of a word triggers an obligatory but capacity demanding operation that results in lexical access and the generation of phonological and semantic codes.

(Herdman \& Paap, 1998, p. 847)

If we restrict ourselves to experiments in which a stimulus is presented at fovea ${ }^{2}$ (so as to respect the boundary condition in the quote above), there are several reports in which the magnitude of the Stroop effect is reduced or eliminated by some simple manipulation. For example, Besner, Stolz, and Boutilier (1997) reported that if only a single letter in a Stroop word is colored (rather than all the letters), the Stroop effect (incongruent-congruent) is reduced by about $25 \%$ relative to the standard condition in which all the letters are colored. The same manipulation eliminated the Stroop effect in a second experiment in which incongruent trials were compared with a neutral baseline consisting of nonwords in which the first letter was shared with a color word in the response set. In another line of experiments, Besner and Stolz (1999c, Experiments 1 and 2) precued a randomly selected single letter position in a word with a small arrow. The cue was 
relevant some of the time (i.e., on a subset of trials some of the letters appeared in one color and other letters appeared in another color, thus necessitating that subjects attend to the cue). Given this context, even words that were homogenous in color yielded a smaller Stroop effect when only a single letter was cued as compared with when all letters were cued. A further experiment that used the spatial cuing manipulation eliminated the Stroop effect when the comparison was between incongruent trials and a neutral baseline consisting of nonwords, in which the cued letter consisted of a color not shared with other letters. Taken together, the results of these four experiments are problematic for the view that visual word recognition is ballistic in the sense that underlying processes can neither be prevented from being initiated nor prevented, even temporarily, from running to completion.

These Stroop experiments have been the object of some criticism (MacLeod, 2000; Marmurek, 1999; Neely \& Kahan, 2001). Some of the criticism pertains to those experiments that used nonwords as a baseline against which incongruent trials were compared. It is probably not productive to debate these criticisms, given that arguments as to which baseline is appropriate have a long history, are not restricted to the Stroop literature, and are unlikely to be resolved in the foreseeable future (e.g., Jonides \& Mack, 1984; Lindsay \& Jacoby, 1994; MacLeod, 1991; Neely \& Kahan, 2001). That said, some readers might wonder why the choice of baseline matters in the present context. After all, Besner et al. (1997, Experiment 1) reported a reduction in the magnitude of the Stroop effect when a single colored letter was compared with a condition in which all letters were colored, and the Stroop effect was defined as the difference between congruent and incongruent trials. Similarly, Besner and Stolz (1999c, Experiments 1 and 2) reported that the Stroop effect was reduced in magnitude when a single letter was precued as compared with when all letters were precued, and the Stroop effect was again defined as the difference between congruent and incongruent trials. Isn't this evidence that some of the word recognition processes associated with retrieval from long-term memory have been derailed at least some of the time?

Neely and Kahan (2001) offer one line of argument as to why a reduction in the size of the Stroop effect (as opposed to its elimination) could be difficult to interpret. In essence, their argument is that part of the Stroop interference effect may reflect response competition that arises from learning during the experiment and that this competition need have nothing to do with retrieval from longterm memory.

Most researchers assume that the standard Stroop interference effect is based on the activation of the word's "semantic" representations, but this need not be so. Stroop interference from color words could be produced entirely by nonsemantic response competition, in which case Stroop interference per se is ill-suited for investigating semantic activation. However, if Stroop interference is produced by both nonsemantic and semantic response competition, one must isolate these two sources of competition to assess the automaticity of each. (pp. 70-71)

There is evidence that semantics plays a role in the Stroop effect when subjects identify the color by overtly naming it (e.g., Davelaar \& Besner 1988; Klein, 1964; Klopfer, 1996; Seymour, 1977; Sharma \& McKenna, 1998; Stirling, 1979). It is also the case that variants of the Stroop task that use a manual response are affected by semantic information (see the Discussion section). However, there is no reason to dismiss the hypothesis that nonsemantic response competition also plays a role in many variants of the Stroop effect. Consequently, the correct interpretation of some of Besner and colleagues' results is unclear-that is, if the Stroop effect is merely reduced in magnitude in an experiment by some manipulation, then it is an open question as to whether semantic processing, nonsemantically based response competition, or both kinds of processing were derailed.

The usual problems associated with failing to reject the null hypothesis notwithstanding, when the Stroop effect is eliminated rather than reduced by some manipulation, this allows the inference that both semantic processing and nonsemantic response competition must have been derailed, if one accepts that semantic processing contributes to a response. To date, however, experiments that respect the boundary condition of foveal presentation have only been able to eliminate the Stroop effect when the neutral baseline consisted of nonwords, but this baseline has been criticized (MacLeod, 2000; Marmurek, 1999; Neely \& Kahan, 2001). It seems unlikely that a neutral baseline exists that would not draw fire from some quarter. What are we left with then, if we dispense with the attempt to find a neutral baseline? The use of congruent trials and defining the Stroop effect as the difference between congruent and incongruent trials is the only remaining possibility (indeed, Lindsay \& Jacoby, 1994, explicitly advocate this). A drawback of this design, however, is that the inclusion of congruent trials provides an incentive for the subject to process the irrelevant word. Consistent with this view, increasing the proportion of congruent trials serves to increase the magnitude of the Stroop effect (e.g., Lowe \& Mitterer, 1982). Is it possible to circumvent the apparent contradiction between trying to arrange conditions so as to show that the Stroop effect can be eliminated, yet use congruent trials as a baseline?

The present experiment combines several factors in an attempt to deter subjects from reading the whole word despite the presence of congruent trials. First, spatial cuing and single letter coloring manipulations were combined in order to make selection within a word more efficient. Second, levels of spatial cuing and coloring were manipulated between subjects rather than within subjects, as in previous experiments. The advantage of this is that set, in terms of the size of a hypothetical attentional window, is held constant across trials, rather than varying between trials. This should make it easier to hold that set from a computational perspective. Finally, a low congruent- 
incongruent trial ratio (20:80) was combined with these manipulations to further dissuade subjects from reading the word.

Three groups of subjects were thus tested in a betweensubjects design. The first group of subjects identified the color of a color word in which all letters were a homogeneous color and all letter positions were spatially precued. The congruent-incongruent trial ratio was 50:50. This can be viewed as the standard baseline condition. A second group of subjects identified the color of a single letter in the word in which the remaining letters appeared in white (a color not in the response set); this same letter was also spatially precued on every trial. The congruentincongruent trial ratio was again 50:50. The third group of subjects was treated identically to the second group of subjects, except that the congruent-incongruent trial ratio was 20:80.

The expected ordering in terms of the size of the Stroop effect across groups is predicated on the results reported by Besner et al. (1997) and Besner and Stolz (1999c). Group 1 should yield the largest Stroop effect, followed by Group 2, which should produce a Stroop effect roughly $50 \%$ smaller. The central question of interest in regard to Group 3 is whether the joint effect of consistent spatial cuing, single letter coloring, and low congruent trial probability is sufficient to eliminate the Stroop effect. To foreshadow the results, a Stroop effect was observed in Groups 1 and 2, with Group 1 showing an effect more than twice the size of that for Group 2. In contrast, Group 3 produced no Stroop effect, consistent with the view that the processing of the irrelevant word is not ballistic in that context.

\section{Is the Irrelevant Word Ever Processed?}

In previous experiments in which the Stroop effect was eliminated, Besner and colleagues concluded that the irrelevant word was not processed at the time that a response to a current trial was made (Besner \& Stolz, 1999b,c; Besner et al., 1997). However, as Besner and Stolz (1999a; Note 1) noted, the elimination of a Stroop effect does not speak to the ultimate fate of the irrelevant word. One way of determining whether the irrelevant word ever gets processed despite the absence of a Stroop effect is by examining whether there is a negative priming effect. ${ }^{3}$

Negative priming in the context of the Stroop paradigm (e.g., Lowe, 1979) refers to the observation that ignoring one stimulus dimension in a display (the so called prime display) interferes with responding to the other stimulus dimension in a subsequent display (the so called target display), if they are related (e.g., ignoring the word $B L U E$ in the prime display and identifying the color blue in the target display).

A negative priming analysis thus provides a means of assessing the issue of whether the irrelevant word in Group 3 is processed despite the observation of no Stroop effect. To foreshadow the results, negative priming is observed. This result is consistent with two accounts. One is that the Stroop effect is not an exhaustive measure of word processing. That is, the observation of no Stroop effect cannot be taken as evidence that the irrelevant word was unprocessed at the time that a response was made to the color on that trial. A different account is that the negative priming effect arises through a distinct perceptual act delayed in time because of the manipulations used here. The latter account is of course inconsistent with the idea that the word is processed ballistically, since such an account denies that processing can be delayed in any way. We return to these issues in the discussion.

\section{METHOD}

\section{Research Subjects}

Forty-eight University of Waterloo psychology undergraduates were each paid $\$ 6.00$ for their participation. All had normal or corrected-to-normal vision and reported themselves to be native English speakers. Group 1 represented a baseline group that provided an estimate of the magnitude of the Stroop effect when single letter coloring and precuing never occurred. These 16 subjects were recruited during the fall term on the University of Waterloo campus. Thirty-two more subjects were recruited during the fall term and were assigned in alternation to Groups 2 and 3.

\section{Design}

Each of the three groups of subjects was presented with both congruent and incongruent color word stimuli. For Group 1, all the letters of all the words were colored, and the ratio of congruent to incongruent trials was 1:1. All letters were spatially cued by an arrow that appeared above and below each letter. These arrow cues appeared $125 \mathrm{msec}$ prior to the display and terminated along with the display when the subject made a response. For Group 2 and Group 3, only a single randomly chosen letter was colored on a trial, and that letter was always spatially cued by an arrow that appeared above the letter position and by a second arrow below that letter position. These arrows also appeared $125 \mathrm{msec}$ prior to the display and terminated when the subject made a response. The ratio of congruent to incongruent trials was 1:1 for Group 2 and 20:80 for Group 3. For all groups each letter in the display was separated by a blank character space. The spacing and spatial cuing set-up was adapted from Besner and Stolz (1999c; Experiment 2).

\section{Stimulus Materials and Test List Construction}

All three groups received 120 test trials in which the subjects were asked to respond to the color of a stimulus presented at fixation. The distractors used were the words red $(9 \mathrm{~mm}$ long $\times 5 \mathrm{~mm} \mathrm{high})$, blue ( $12 \mathrm{~mm}$ long $\times 5 \mathrm{~mm}$ high), green ( $15 \mathrm{~mm}$ long $\times 4 \mathrm{~mm}$ high), and yellow (18 $\mathrm{mm}$ long $\times 6 \mathrm{~mm}$ high). The words were presented in Micro Experimental Lab (MEL; Schneider, 1988) romantri.fnt font, which is a graphical version of the standard MEL font. The colors used were red (RGB 42, 0, 0), blue (RGB 21, 21, 23), green (RGB 0,42, 0), and yellow (RGB 63, 63, 21). The noncolored letters were presented in MEL white (RGB 63, 63, 63).

Each of the three groups of subjects responded to 120 experimental trials. There was an equal number of congruent (60) and incongruent trials (60) in Groups 1 and 2. For Group 3, for 20\% of the trials were congruent (24) and $80 \%$ were incongruent (96). All pairings of color and word were used equally often within a group. All conditions were randomly intermixed within each group, and each subject received a different random order of trials. A set of 40 practice trials was also constructed to meet the experimental trial constraints for each group. Administration of the practice trials preceded the experiment proper. 


\section{Procedure}

The subjects were tested individually and were seated approximately $45 \mathrm{~cm}$ from a computer monitor. Task instructions were displayed on the monitor and were also relayed orally by the experimenter. Stimuli were displayed on a Microscan 4V/AD1 color monitor controlled by MEL software implemented in a Vault Pentium 100 computer.

The subjects were instructed to ignore the distractor word and to respond to the displayed color of the stimulus. Responses were made with the left and right hands by depressing a key covered with an appropriately colored piece of paper. The colored paper covered the " $z$," "x," ">," and "/" keys and were red, blue, yellow, and green, respectively. A response terminated the stimulus display and initiated a 400-msec intertrial interval, during which time the screen remained blank. The MEL software recorded reaction time (RT) to the nearest millisecond and response accuracy.

The subjects were given the opportunity to ask questions following the practice phase and were instructed to perform the task as quickly and as accurately as possible.

\section{Results}

Only RT data from correct responses were analyzed. Before any statistical analyses were conducted, the RT data were subjected to a recursive trimming procedure in which the criterion cutoff for outlier removal is established independently for each subject, in each condition, by reference to the sample size in that condition(Van Selst \& Jolicœur, 1994). This trimming procedure resulted in $3.5 \%$ of the correct RT data's being discarded for Group 1, $2.4 \%$ for Group 2, and $2.4 \%$ for Group 3. The trimmed mean RTs and percentage error for each condition in each group are displayed in Table 1 .

Stroop effect. The 93-msec Stroop effect in Group 1 was significant $\left[F(1,15)=11.6, M S_{\mathrm{e}}=6,000.29, p<\right.$ $.005]$, as was the 39-msec Stroop effect in Group 2 $\left[F(1,15)=14.6, M S_{\mathrm{e}}=823.11, p<.005\right]$. In contrast, the 1-msec Stroop effect for Group 3 was not significant $(F<1)$. The $1.5 \%$ Stroop effect in the error data approached significance for Group $1\left[F(1,15)=3.4, M S_{\mathrm{e}}=4.976\right.$, $p<.08]$. There were no significant error effects for Groups 2 and $3\left(F_{\mathrm{s}}<1\right)$.

The usual concern about statistical power (Is the 1msec effect observed for Group 3 smaller than the 39-msec effect observed for Group 2?) was addressed by a 2 factor analysis of variance (ANOVA) with group as a betweensubjects factor (Group 2 vs. 3) and congruency as a withinsubjects factor (congruent vs. incongruent). The interaction between groups and congruency was significant $\left[F(1,30)=5.02, M S_{\mathrm{e}}=1,143, p<.05\right]$.

It might be argued that the absence of a Stroop effect in Group 3 reflects nothing more than too much variabil-

Table 1

Mean RTs (in Milliseconds) and Percentage Errors According to Conditions for Groups 1, 2, and 3

\begin{tabular}{|c|c|c|c|c|c|c|}
\hline \multirow[b]{3}{*}{ Condition } & \multicolumn{6}{|c|}{ Group } \\
\hline & \multicolumn{2}{|c|}{1} & \multicolumn{2}{|c|}{2} & \multicolumn{2}{|c|}{3} \\
\hline & RT & $\% \mathrm{E}$ & RT & $\% \mathrm{E}$ & RT & $\% \mathrm{E}$ \\
\hline Incongruent & 753 & 3.4 & 723 & 3.0 & 759 & 2.3 \\
\hline Congruent & 660 & 2.0 & 684 & 2.9 & 758 & 2.9 \\
\hline Difference & 93 & 1.4 & 39 & 1.0 & 1 & -.6 \\
\hline
\end{tabular}

ity in the congruent condition because of too few trials per se, rather than the congruent/incongruent trial ratio's being low. This point was addressed by randomly sampling 24 corresponding congruent trials from the 60 congruent trials in Group 2. The mean RT for these congruent trials in Group 2 was 677, yielding a 46-msec Stroop effect $\left[F(1,15)=13.38, M S_{\mathrm{e}}=1,273.88, p<.005\right]$, despite the fact that this experiment was less powerful than that for Group 3 in that there were fewer incongruent trials (60 instead of 96). The interaction between group (Group 2 vs. 3$)$ and congruency was also significant $[F(1,15)=$ $\left.5.98, M S_{\mathrm{e}}=1,368.39, p<.05\right]$.

Negative priming. Given that Group 3 produced no evidence of a Stroop effect, a negative priming analysis was conducted in order to address the issue of whether the irrelevant word was ever processed. The incongruent trials for Group 3 were therefore divided into two sets. All incongruent trials in which a stimulus was preceded by an incongruent trial on which the response was correct were classified either as related, in which case the irrelevant word on the previous trial was the same as the color on the current trial, or as unrelated, in which case the irrelevant word on the previous trial was different from the color on the current trial. This classification yielded a 52-msec difference in RT, with related trials $(796 \mathrm{msec})$ being slower than unrelated trials $(744 \mathrm{msec})[t(15)=$ $2.64, p<.05]$. There was a small error difference in the opposite direction $($ related $=1.4 \%$, unrelated $=2.3 \%)$, but this difference was not significant $[t(15)=1.3, p>.20]$.

\section{Discussion}

The magnitude of the Stroop effect varied predictably across groups, being largest $(93 \mathrm{msec})$ for Group 1 for which all letters were the same color, all letters were spatially cued prior to the color word's onset, and the congruent-incongruent trial ratio was 50:50. The next largest Stroop effect ( $39 \mathrm{msec}$ ) was observed for Group 2 for which a single letter position was spatially cued prior to the word's onset, that letter was the only one colored in the display, and the congruent-incongruent trial ratio was 50:50. Group 3, for which stimulus conditions were the same as Group 2 except that the congruent-incongruent trial ratio was 20:80, produced a nonsignificant $1-\mathrm{msec}$ Stroop effect. It thus appears possible to eliminate the Stroop effect, even when it is defined as the difference between congruent and incongruent trials and a single word appears at fovea. The results from Group 3 thus constitute an example in which the concern about baseline voiced by MacLeod (2000), Marmurek (1999) and Neely and Kahan (2001) is obviated.

\section{Does Semantic Processing Play a Role in the Stroop Effect When Manual Responses are Used?}

It could be, as suggested by Neely and Kahan (2001), that semantic knowledge is activated but plays no role in the task. According to this account, what was eliminated in the Group 3 data is merely nonsemantic response competition. A difficulty with this hypothesis is that there is evidence of semantic level involvement in Stroop tasks 
with manual responses. For example, McKenna and Sharma (1995) reported a series of five experiments in which irrelevant words that evoked negative cognitions/ emotions were associated with slower color identification time than were neutral words. Sharma and McKenna (1998) reported another experiment in which one group of subjects named colors and ignored the carrier word, and another group of subjects used a keypress to identify the color. A standard Stroop effect was seen in the vocal condition (incongruent RT > neutral RT), and critically, color words that were not part of the response set were also significantly slower than neutral words. The identical pattern was present in the manual condition, but Sharma and McKenna asserted that there was no significant difference between the neutral words and color words that were not in the response set (and therefore argued that semantic processing played no role). However, this difference was $40 \mathrm{msec}[t(39)=3.3, p<.003] .{ }^{4}$ The results of these six experiments are thus consistent with the conclusion that semantics play a role in a manual response version of the Stroop task, and therefore the inference from the elimination of the Stroop effect in the present experiment is that semantic processing was blocked, at least temporarily.

\section{Where Are We Then Theoretically in Regard to the Elimination of the Stroop Effect?}

The standard account of the Stroop effect in hundreds of textbooks, chapters, and refereed journal articles asserts that processing from feature extraction through to semantics cannot be interrupted at any point. Processing is thus said to be ballistic. This account makes no provisions for the observation that the Stroop effect can be reduced, and even eliminated, as in the present experiments.

If the standard ballistic account cannot explain these results, then how should they be explained? The account advanced here is that lexical-semantic processing typically reflects the default set, which subjects (unconsciously) adopt. However, the default set can be overridden in a variety of ways. A sufficient account of the present data is that the spatial cuing manipulation probabilistically narrows the spatial attention window to a single letter and that the single letter coloring manipulation also probabilistically restrains subjects from treating the stimulus as a word, 5 and, when combined with a low congruent trial probability, further serves to dissuade subjects from reading the word. Hence, the Stroop effect disappears.

\section{Which Word Recognition Processes Are Ballistic and Which Are Not?}

It is important to recognize that different theorists treat the notion of ballistic processing differently. For example, Frost (1998) views phonological processing as obligatory and ballistic. He might therefore argue that the present results (as well as the previous ones discussed here) show only that it is possible to prevent lexical and/or semantic representations from being activated, but that there is no direct evidence that prior phonological processing of the entire string can be derailed. In contrast, Neely and Kahan (2001) take the position that results such as the ones discussed here can be construed as evidence that processing prior to semantics is not ballistic. They argued that, in order to prove that the spread of purely semantic activation from one node to another is not ballistic, it must be shown that semantic processing is disrupted in a context in which prior lexical level processing is intact. ${ }^{6}$

The main point to be taken away from the present discussion is that whose ox is being gored depends on the details of the theoretical position that one holds. That said, we should not lose sight of the main point of the present experiments. The elimination of the Stroop effect in the present context is evidence that all reading processes at the single-word level in skilled readers are not, as widely claimed, ballistic.

Converging evidence that word recognition is not ballistic comes from four other paradigms. In the spatial cuing paradigm, the location of an upcoming target is probabilistically signaled, typically by an abrupt onset at that location. Here, an invalid cue bottlenecks some aspect of word recognition in that a constant amount of time is added to lexical decision relative to a valid cue (McCann, Folk, \& Johnston, 1992; Stolz \& McCann, 2000). Spatial cuing within a word also has a dramatic effect; Johnston (1981) reported that the word superiority effect in perceptual identification is eliminated if a single letter position is precued. Relatedly, the word frequency effect in naming and lexical decision is bottlenecked in the context of the psychological refractory period paradigm (i.e., word frequency and stimulus onset asynchrony are additive factors; McCann, Remington, \& Van Selst, 2000; see also Besner \& Jolicœur, 2001). Finally, semantic priming in the context of lexical decision can be eliminated if subjects search the prime for the presence of a target letter (e.g., see Stolz \& Besner, 1998, for new findings and a review of much of this literature). This approach has been extended by Brown, Roberts, and Besner (in press) who reported that a foveally presented but irrelevant word also fails to produce priming when subjects must search another prime word for the presence or absence of a target letter. All of these findings are consistent with the claim that ballistic processing is the exception rather than the rule. Neumann (1984) has made much the same general point in a frequently overlooked review.

\section{New Directions: How Should a Negative Priming Effect in the Absence of a Stroop Effect be Understood?}

Finally, there is the fact that the data for Group 3 yielded negative priming in the complete absence of a Stroop effect. Three accounts of this dissociation can be offered.

The first is simply that this dissociation implies that the Stroop effect is not an exhaustive measure of word recognition. In this account, the negative priming observed here is an index of processing of the irrelevant word that took place prior to the point in time that a re- 
sponse identifying the color on the current trial was made (e.g., see the inhibition account offered by Tipper, 1985). Of course, this account begs the obvious question: if the irrelevant word was processed on line, why is the Stroop effect eliminated?

A second account is that processing of the irrelevant word was slowed under these narrow attentional focus conditions and therefore did not have time to interfere with color identification on the current trial. This would be consistent with Herdman and Paap's (1998) assertion that word processing at fovea is obligatory but capacity demanding, if most (but not all) of the capacity is allocated to the cued part of the word (though note that Neely \& Kahan, 2001, assert that semantic activation is capacity free). One problem with this account is that a Stroop effect is seen under certain conditions despite coloring only a single letter or element (Besner \& Stolz, 1999a, Experiment 3; 1999b, Experiment 2).

A third account is that negative priming arises because of backwards retrieval of information from the prime display (trial $N$ ) during target display (trial $N+1$ ) processing (see Milliken, Joordens, Merikle, \& Seiffert, 1998; Neill, 1997). The details of this account need not concern us here. The main point to be made in the present context is that the analysis of the prime display that gave rise to the negative priming for Group 3 could take place after a response to the current trial has been made. What is up for grabs is what kind of information (i.e., lexical or semantic) was processed, when it was processed, and whether such processing is inevitable.

\section{CONCLUSIONS}

The present results again suggest that the widely accepted ballistic processing account of the Stroop effect is not correct. A sufficient account of Group 3's data is that the combined set of manipulations used here served to prevent, at least temporarily, activation of lexical/ semantic representations in long-term memory, with the consequence that a Stroop effect was not observed.

The present observations may lead to renewed interest in negative priming in the context of Stroop's paradigm. Determining when and what kind of analysis of the irrelevant word in the prime display occurs under the present conditions seems a useful direction for further research.

\section{REFERENCES}

BeSNer, D., \& Joliceur, P. (2001). Visual word recognition is not ballistic: Evidence from the Psychological Refractory Paradigm. (Manuscript in preparation).

Besner, D., \& Stolz, J. A. (1999a). Context dependency in Stroop's paradigm: When are words treated as nonlinguisticobjects? Canadian Journal of Experimental Psychology, 53, 374-380.

Besner, D., \& Stolz, J. A. (1999b). Unconsciously controlled processing: The Stroop effect reconsidered. Psychonomic Bulletin \& Review, 6, 449-455.

Besner, D., \& Stolz, J. A. (1999c). What kind of attention modulates the Stroop effect? Psychonomic Bulletin \& Review, 6, 99-104.

Besner, D., Stolz, J. A., \& Boutilier, C. (1997). The Stroop effect and the myth of automaticity. Psychonomic Bulletin \& Review, 4, 221-225.
Brown, M., Roberts, M., \& Besner, D. (in press). Semantic processing in visual word recognition: Activation blocking and domain specificity. Psychonomic Bulletin \& Review.

DavelaAr, E., \& Besner, D. (1988). Word identification: Imageability, semantics and the content-functor distinction. Quarterly Journal of Experimental Psychology, 40A, 789-799.

FROST, R. (1998). Towards a strong phonological theory of reading: True issues and false trails. Psychological Bulletin, 1, 71-99.

Herdman, C., \& PaAp, K. R. (1998). Highly skilled participants and failures to redirect attention: Two plausible reasons for failing to replicate Paap and Noel's effect. Journal of Experimental Psychology: Learning, Memory, \& Cognition, 24, 845-861.

Johnston, J. C. (1981). Effects of advance precuing of alternatives on the perception of letters alone and in words. Journal of Experimental Psychology: Human Perception \& Performance, 7, 560-572.

JONIDES, J., \& MACK, R. (1984). On the cost and benefit of cost and benefit. Psychological Bulletin, 96, 29-44.

Kahan, T., Neill, W. T., Mathis, K. M., \& Verwys, C. (1996, November). Is elimination of Stroop interference evidence against automaticity? Poster session presented at the 37 th annual meeting of the Psychonomic Society, Chicago.

KLEIN, G. S. (1964). Semantic power measured through the interference of words with color naming. American Journal of Psychology, 77, 576-588.

KLOPFER, D. S. (1996). Stroop interference and color-word similarity. Psychological Science, 7, 150-157.

LiNDSAY, D. S., \& JACOBY, L. L. (1994). Stroop process dissociations: The relationship between facilitation and interference. Journal of Experimental Psychology: Human Perception \& Performance, 20, 219 234.

Lowe, D. G. (1979). Strategies, context, and the mechanism of response inhibition. Memory \& Cognition, 7, 382-389.

Lowe, D. G., \& MitTerer, J. O. (1982). Selective and divided attention in a Stroop task. Canadian Journal of Psychology, 36, 684-700.

MacLeod, C. M. (1991). Half a century of research on the Stroop effect: An integrative review. Psychological Bulletin, 109, 163-203.

MacLeod, C. M. (1992). The Stroop task: The "gold standard" of attentional measures. Journal of Experimental Psychology: General, 121, 12-14.

MacLeod, C. M. (2000, July). Putting automaticity in context: Reducing the Stroop effect. Paper presented to the joint meeting of the Experimental Psychology Society and the Canadian Society for Brain, Behaviour and Cognitive Science, Cambridge, England.

Marí-Beffa, P., Estévez, A. F., \& Danziger, S. (2000). Stroop interference and negative priming: Problems with inferences from null results. Psychonomic Bulletin \& Review, 7, 499-503.

MARMUREK, H. (1999, November). Response modalitymodulates singleletter effects in color-word interference. Poster presented at the 40th annual meeting of the Psychonomic Society, Los Angeles.

McCann, R. S., Folk, C. L., \& Johnston, J. C. (1992). The role of spatial attention in visual word processing. Journal of Experimental Psychology: Human Perception \& Performance, 18, 1015-1029.

McCann, R. S., Remington, R. W., \& Van Selst, M. (2000). A dual task investigation of automaticity in visual word processing. Journal of Experimental Psychology: Human Perception \& Performance, 26, 1352-1370.

McKenna, F. P., \& Sharma, D. (1995). Intrusive cognitions: An investigation of the emotional Stroop task. Journal of Experimental Psychology: Learning, Memory, \& Cognition, 21, 1595-1607.

Milliken, B., Joordens, S., Merikle, P. M., \& Seiffert, A. (1998). Selective attention: Re-evaluating the implications of negative priming. Psychological Review, 105, 203-229.

NeELY, J. H., \& KAHAN, T. (2001). Is semantic activation automatic? A critical reevaluation. In H. L. Roediger III, J. S. Nairne, I. Neath, \& A. M. Surprenant (Eds.), The nature of remembering: Essays in honor of Robert G. Crowder (pp. 69-93). Washington, DC: American Psychological Association.

NeILL, W. T. (1997). Episodic retrieval in negative priming and repetition priming. Journal of Experimental Psychology: Learning, Memory, \& Cognition, 23, 1291-1305.

Neumann, O. (1984). Automatic processing: A review of recent findings 
and a plea for an old theory. In W. Prinz \& A. F. Sanders (Eds.), Cognition and motor processes (pp. 255-293). Berlin: Springer-Verlag.

SCHNEIDER, W. (1988). Micro Experimental Laboratory: An integrated system for IBM PC compatibles. Behavior Research Methods, Instruments, \& Computers, 20, 206-217.

Seymour, P. H. K. (1977). Conceptual encoding and the locus of the Stroop effect. Quarterly Journal of Experimental Psychology, 29, 245-265.

Sharma, D., \& McKenna, F. P. (1998). Differential components of the manual and vocal Stroop tasks. Memory \& Cognition, 26, 1033-1040.

STIRLING, N. (1979). Stroop interference: An input and an output phenomenon. Quarterly Journal of Experimental Psychology, 31, 121-132.

Stolz, J. A., \& Besner, D. (1998). Levels of representation in visual word recognition: A dissociation between morphemic and semantic processing. Journal of Experimental Psychology: Human Perception \& Performance, 24, 1642-1655.

Stolz, J. A., \& McCann, R. S. (2000). Visual word recognition: Reattending to the role of spatial attention. Journal of Experimental Psychology: Human Perception \& Performance, 26, 1320-1331.

Stroop, J. R. (1935). Studies of interference in serial verbal reactions. Journal of Experimental Psychology, 18, 643-661.

TipPER, S. P. (1985). The negative priming effect: Inhibitory priming by ignored objects. Quarterly Journal of Experimental Psychology, 37A, 571-590.

VAn Selst, M., \& Joliceur, P. (1994). A solution to the effect of sample size on outlier elimination. Quarterly Journal of Experimental Psychology, 47A, 631-650.

\section{NOTES}

1. Statistically eliminated; there may be some small effect that is difficult to detect.

2. However, other variants of Stroop's paradigm in which a neutral word is presented at fixation and a color word (appearing in white) is presented immediately above or below the word at fixation have failed to yield a Stroop effect (incongruent-congruent) when only a single letter in the neutral word is colored (Besner \& Stolz, 1999b) and, indeed, even when all the letters in a neutral word are colored (Besner \& Stolz, 1999a, Experiment 4).
3. To be sure, this question is not new. In an unpublished study, Kahan, Neill, Mathis, and Verwys (1996) reported that the status of the irrelevant word on trial $N$ affects RT on trial $N+1$. However, one problem with their design is that it contained $50 \%$ congruent trials; we know from Besner et al. (1997) that the single color letter manipulation does not eliminate the Stroop effect under these conditions. This raises the possibility that the negative priming in the single colored letter condition reflects processing that occurred on those trials that produced a Stroop effect. A related problem is that including congruent trials in the negative priming analysis risks the effect's being driven by processing which is indeterminant (a response on a congruent trial could be based on mistakenly processing the word instead of the color, but an incorrect response would not be seen). More generally, the observation of negative priming only shows that some aspect of the word was processed. Whether such processing is lexical or both lexical and semantic would need to be determined. Negative priming was also investigated by Marí-Beffa, Estévez, and Danziger (2000). These authors reported two experiments in which there was negative priming following trials in which only a single letter in the word was colored. They therefore concluded that the word on the prime trial was automatically processed. The difficulty here is that the "prime" trials failed to demonstrate a dissociation in Stroop effects between all colored and single letter colored conditions (either in presence or in magnitude) in both experiments. In order for a negative priming effect to be analytic, it would have been useful to show that the prime trials produced no Stroop effect for the single color letter condition combined with a Stroop effect for the all colored condition.

4. I thank Dinkar Sharma for providing the individual subject data and for confirming the analysis reported here.

5. It would be parsimonious to conceptualize the single colored letter manipulation as just another way of manipulating spatial attention, but Besner and Stolz (1999a,b) argue that its effect should not be explained in this way.

6. Stolz and Besner's (1998) report of a 55-msec morphemic priming effect but no semantic priming in the same experiment presents a problem for this argument.

(Manuscript received December 2, 1999; revision accepted for publication July 27, 2000.) 